\title{
Proyecto comunitario (turístico-cultural): Boulevard Maroya. (validación).
}

\section{(c) (i) (9)(2)}

Community Project (tourist-cultural): Boulevard Maroya. (Validation).

Medinilla Sarduy, Alexis. ${ }^{1}$ \& Efraín Velasteguí López. ${ }^{2}$

Recibido: 10-03-2017 / Revisado: 16-05-2017 Aceptado: 02-06-2018/ Publicado: 01-07-2018

\begin{abstract}
.
DOI: $\underline{\text { https://doi.org/10.33262/cienciadigital.v2i3.145 }}$

This article presents the results of the research carried out in the city of Cienfuegos. Taking into account the previous results achieved in the research that precedes this validation, the operational design of the Community Project (Tourist-Cultural) is done: Boulevard Maroya.

In this way, the council of the provincial administration of Cienfuegos will be provided with a tool that will make it possible to insert the studied zone into the integral development of the historic center of the city.
\end{abstract}

Keywords: Validation, Project, Community, Council, Administration.

\section{Resumen.}

El presente artículo presenta los resultados de la investigación realizada en la ciudad de Cienfuegos. Teniendo en cuenta los resultados previos alcanzados en a la investigación que antecede esta validación, se realiza el diseño operativo del Proyecto Comunitario (Turístico-Cultural): Boulevard Maroya.

De esta forma, se dotará al consejo de la administración provincial de Cienfuegos de una herramienta que posibilitará insertar la zona estudiada al desarrollo integral del centro histórico de la ciudad.

Palabras Claves: Validación, Proyecto, Comunitario, Consejo, Administración.

${ }^{1}$ Universidad de La Habana, Facultad de Turismo, La Habana, Cuba, alexlester.medy@gmail.com ${ }^{2}$ Universidad Técnica de Cotopaxi, Ext. La Maná, Cotopaxi, Ecuador, luis.velastegui7838@utc.edu.ec 


\section{Introducción.}

Por su lado, el antes citado PMBOK del Project Management Institute lo define como "el arte de dirigir y coordinar los recursos humanos y materiales, a lo largo del ciclo de vida del Proyecto, mediante el uso de las actuales técnicas del Management, para conseguir los objetivos prefijados de alcance, coste, plazo, calidad y satisfacción de los partícipes o partes interesadas en el Proyecto".

Existen muchos conceptos de proyecto, para Zamora, (2009), también puede ser definido como "cualquier actividad con punto de comienzo y con objetivos definidos mediante los que se identifican su terminación".

La Norma Cubana ISO/CD 10006 lo define como "proceso único que consiste en un conjunto de actividades coordinadas y controladas, con fechas de inicio y terminación, destinadas a lograr un objetivo en conformidad con requisitos específicos, incluyendo las limitaciones impuesta por el tiempo, el costo y los recursos".

Los Proyectos constituyen actividades multidisciplinares que forman un sistema. Bien es verdad que pueden existir Proyectos simples en los que entran en su formación pocas disciplinas o actividades. También habrá que considerar que cada disciplina o actividad que integra un proyecto tiene el carácter de subsistema del mismo y normalmente, siempre existe una interrelación entre todos ellos. Por tanto y debido, además al ya indicado carácter temporal del sistema Proyecto se puede afirmar que se trata siempre de un sistema complejo y dinámico al que hay que aplicar un procedimiento de Dirección Integrada o "Management" a lo largo de toda su vida con el fin de obtener una optimización de todos los recursos empleados a través de su estructura de organización.

Una vez aplicado el instrumento diseñado y encuestado a los pobladores de la zona objeto de estudio, estos demuestran la aceptación, en gran medida, de la incorporación de acciones que contribuyan a mejorar sus condiciones de vida y aseguran que estas mejoras, vinculadas con el turismo en esa zona, brindan beneficios sustanciales y equitativos en toda la comunidad.

Asumiendo los resultados obtenidos en la investigación que precede a este artículo, el objetivo general del mismo es: Validar el procedimiento creado para los proyectos comunitarios en el Proyecto Boulevard Maroya.

\section{Desarrollo.}


La ejecución de un proyecto es un proceso genérico y universal, aunque cada organización en su ambiente de trabajo es diferente y emplea estrategias de ejecución distintas que se adaptan de la mejor manera al tamaño, tipo, complejidad, entorno, exigencias de las partes interesadas y del momento. Sin embargo, bajo cualquier esquema de trabajo, existen fases básicas en la vida de un proyecto.

Figura No. 1: Fases y actividades definidas para el Proyecto Comunitario (turísticocultural): Boulevard Maroya.

\begin{tabular}{|l|}
\hline Fase 1: \\
\hline$\frac{\text { Conceptualización/ }}{\text { Inicio }}$ \\
\hline -1- Análisis de la \\
situación problémica. \\
-2- Establecimiento de \\
la finalidad del \\
proyecto. \\
-3- Establecimiento del \\
Objetivo General. \\
-4- Identificación de \\
las partes \\
interesadas. \\
-5- Análisis de las \\
necesidades de los \\
clientes. \\
-6- Análisis previo del \\
alcance del proyecto. \\
-7- Estudio de \\
viabilidad inicial. \\
\hline
\end{tabular}

\begin{tabular}{l}
\hline$\frac{\text { Fase 2: Diseño de }}{\text { configuración/ }}$ \\
\hline Planificación \\
\hline 1- Descripción \\
detallada del \\
proyecto. \\
-2- Diseño operativo. \\
-3- Gestión de riesgo. \\
-4- Formación del \\
equipo del proyecto. \\
-5- Certificación del \\
proyecto. \\
-6- Elaboración del \\
manual de dirección \\
del proyecto. \\
-7- Definición de los \\
subsistemas del \\
proyecto. \\
-8- Estudio de \\
prefactibilidad. \\
\hline
\end{tabular}

\begin{tabular}{|l|}
\hline \multicolumn{1}{|c|}{ Fase 3: Organización } \\
\hline de la ejecución \\
\hline -1- Asignación y \\
secuenciación de las \\
tareas. \\
-2- Establecer la \\
programación en \\
tiempo y recursos. \\
-3- Cálculo del objetivo \\
costo. \\
-4- Garantizar un \\
sistema de gestión y \\
control de la \\
configuración a partir \\
de indicadores. \\
-5- Estudio de \\
factibilidad. \\
\hline
\end{tabular}
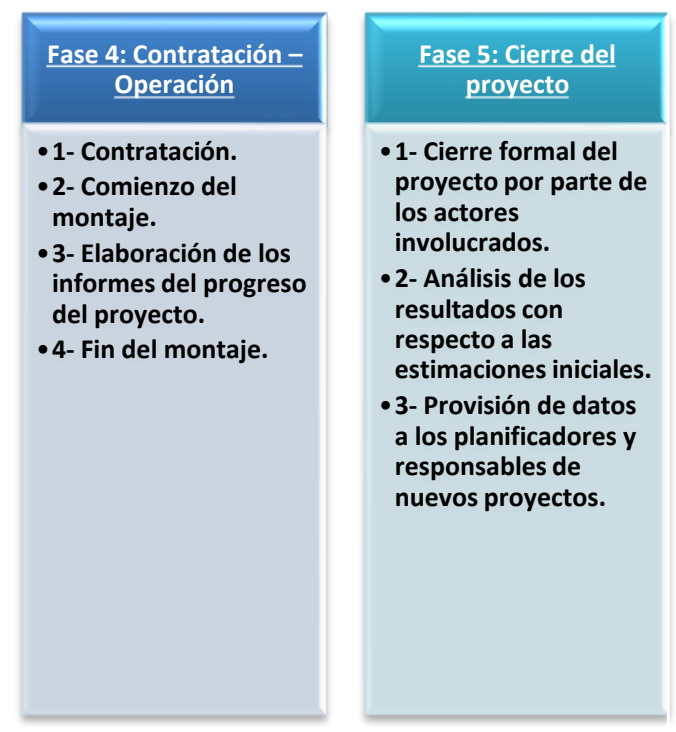

Fuente: Elaboración propia.

A continuación, se explicitan las descripciones de las actividades que corresponde realizar en cada fase de un proyecto de carácter industrial aplicado a los proyectos turísticos comunitarios. Se insiste en señalar que en los proyectos actuales pueden estar superpuestas algunas fases principalmente las que corresponden a las de definición e implantación.

Presentación del proyecto comunitario (turístico-cultural): Boulevard Maroya.

Fase 1: Conceptualización/Inicio. 
1. Análisis de la situación problémica: (árbol de problemas) Es un análisis en el que se detectan proactivamente problemas u oportunidades que pueden ser solucionados o aprovechadas mediante proyectos turísticos.

Figura No. 2: Árbol de problemas.

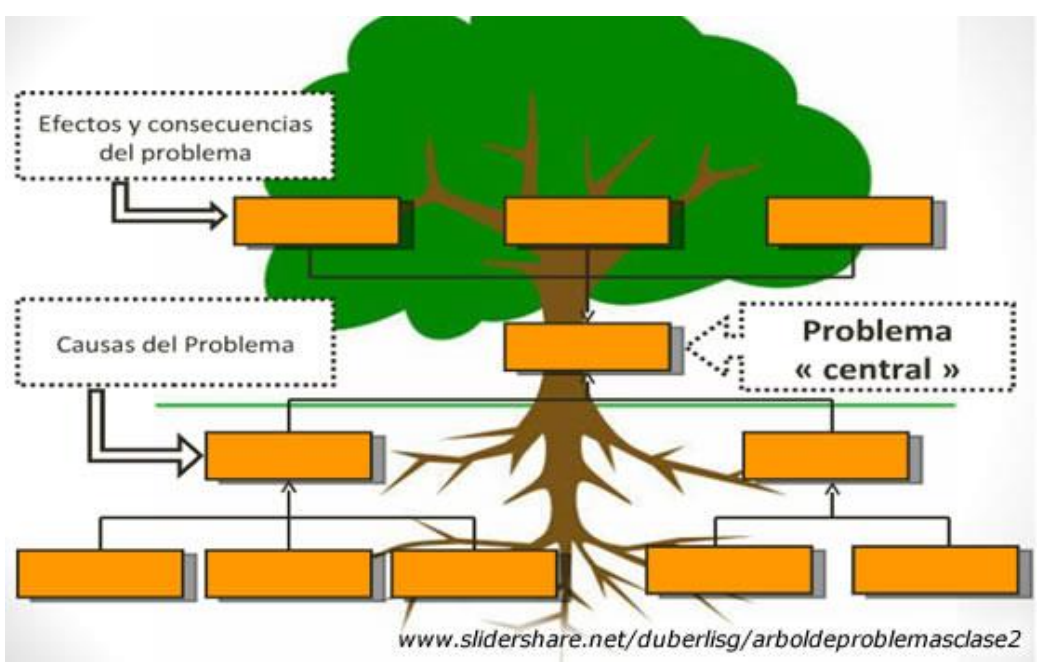

Fuente: Tomado de www.slidershare/duberlisg/arboldeproblemasclase2

Tomándose como base el diagnóstico realizado de la zona objeto de estudio:

\section{Problema central:}

Abandono y deterioro de la zona objeto de estudio.

\section{Causas del problema:}

- Insuficiente atención por parte del gobierno provincial.

- Aumento de la delincuencia por el no seguimiento de la PNR ante hecho delictivos.

- Poco interés por parte de la Oficina de Conservación Patrimonial.

- Escasa responsabilidad medioambiental por parte del gobierno y de las industrias enclavadas en la zona.

\section{Efectos del problema:}

- Deterioros en las fachadas de las viviendas. 
- Contaminación en las aguas de la bahía.

- Vertederos de desechos en las esquinas.

- Marginalidad y violencia en la zona. (asalto a visitantes, violencia de género)

- Bajo nivel de conservación de sitios con valores históricos y patrimoniales.

- Escasa iluminación en las calles.

- Escasa oferta gastronómica.

2. Establecimiento de la finalidad del proyecto:

Finalidad: Proponer una herramienta al Consejo de la Administración Provincial que permita insertar a la población local de la zona objeto de estudio del centro histórico de la ciudad de Cienfuegos, al desarrollo económico del área.

3. Establecimiento del Objetivo General:

Objetivo general: Diseñar el Boulevard Maroya en 1 año, con el presupuesto estimado por el Consejo de la Administración Provincial para el desarrollo local.

En la presente investigación no se propone un presupuesto ya que existen limitaciones en la recopilación de información de proyectos similares por la sensibilidad de datos, por la dificultad de desagregar los costos de los deferentes subproyectos. Además, partir del estudio de campo, se conoce que los proyectos comunitarios similares han respondido a intereses privados limitándose la publicación de datos.

4. Identificación de las partes interesadas: Como resultado de una reunión quedan identificadas las siguientes partes interesadas:

- Clientes finales: Las personas que utilizan el producto que afecta de forma directa a la capacidad de satisfacer sus necesidades. Es necesario comprender las necesidades, expectativas y los requisitos de las personas. Se debe conocer cómo utilizarán el producto. Los clientes son unas de las partes interesadas más importantes.

- Gobierno provincial y municipal y organizaciones gubernamentales

Muchas empresas tienen requisitos legales que sus productos y servicios deben cumplir. No puede generar un elevado costo para que sea imposible cumplirlos. Las organizaciones interesadas se encuentran: Delegación provincial del Turismo, Oficina Provincial de Conservación del Patrimonio y la Dirección Provincial de Planificación Física. 
- Empleados del proyecto: Se consideran empleados los que trabajen en la construcción de la infraestructura, así como los que trabajen finalmente en el Boulevard. Estos serán los trabajadores de la Empresa Constructora de Obras de Ingeniería \# 12, Palmares, Cubacel, Artex, Dirección Provincial de Cultura, Asociación Cubana de Artistas y Artesanos, Infotur, Formatur y los escultores locales.

5. Análisis de las necesidades de los clientes:

Necesidades y expectativas de los clientes intermedios: gobiernos provincial y municipal. Mediante debates previos, tormentas de ideas y conversaciones con expertos se definieron como necesidades:

- Diversificación de la oferta de servicios a la comunidad.

- Disminución de los delitos vandálicos.

- Que se vele por los intereses de los cruceristas.

- Que se contrarresten los malos vicios que pueden desencadenar ese futuro desarrollo turístico.

Necesidades y expectativas de los clientes finales: comunidad (mediante el estudio de campo y la aplicación de la encuesta) se definieron como necesidades:

- Aumento de la calidad de vida.

- Mejora de la infraestructura de las fachadas de las viviendas.

- La proliferación de negocios.

- Generación de empleos.

Los cruceristas, (mediante conversaciones con agencias receptivas en Cienfuegos, así como la búsqueda en internet del estado de opinión de los cruceristas que han arribado a Cienfuegos), se definieron como necesidades:

- Historia.

- Patrimonio.

- Religión.

- Venta de artículos artesanales, así como artículos que reflejen lo antes mencionados.

- Información.

6. Análisis previo del alcance del proyecto:

Teniendo en cuenta el OG el alcance va: desde la definición de la situación que origina el proyecto hasta el cierre formal del mismo y esté listo para operar como boulevard. 
7. Estudio de viabilidad inicial:

La técnica PESTEL: Se aplicó la técnica PESTEL para identificar los factores que describen el entorno favorable para la realización del proyecto. Teniéndose en cuenta en lo:

- Político:

- Las políticas de los gobiernos locales y nacional en función de la realización de proyectos.

- La política fiscal del país (ley 118: Ley de Inversión Extranjera emitida por la Gaceta Oficial de la República de Cuba) refiere en varios de sus capítulos y artículos correspondientes la necesidad de realización y evaluación de proyectos, así como de investigaciones que muestren su factibilidad.

- Económico:

- El ciclo económico de país. (PIB) La evolución económica del país en el 2015 fue sin duda favorable al lograrse un crecimiento del 4,3\% en el PIB. Tomado de Una primera mirada a la economía cubana: Resultados de 2015 y perspectivas de 2016. Doctor en Ciencias Económicas José Luis Rodríguez.

- Las nuevas políticas económicas del país. (En el proceso de Actualización del Modelo Económico Cubano y en los Lineamientos ${ }^{3}$ de la Política Económica y Social aprobados en el marco del 6to Congreso del PCC, se pretende promover un conjunto de transformaciones (tanto a nivel macro como micro), en varios aspectos que van desde lo empresarial y lo territorial hasta algunas cuestiones sociales más significativas. En cuanto al ámbito local, pudiera interpretarse que estos tributan a su fortalecimiento y que a la postre constituye un reto).

\section{- Sociocultural:}

- Cambios de preferencias que repercuten en el nivel de consumo. Ver necesidades de los clientes finales.

- Rasgos culturales de interés. Mitos, leyendas, religión y personajes importantes.

${ }^{3} 2,5,21,22,37,120,133,134,142,150,178,180,182,185,197,204,205,235,239,247,264$, 293 y 294 
Tecnológico:

- Infraestructura tecnológica del área: redes wifi en las cercanías al área.

\section{- Ecológico:}

- Leyes de protección medioambiental: La Ley No. 81, aprobada en el 1997 por el Parlamento Cubano brinda la base para una acertada estrategia ambiental en las condiciones que el necesario desarrollo sostenible demanda y para la inserción armónica de múltiples instrumentos políticos, científicos, tecnológicos, jurídicos, educativos y de gestión en un sistema integrado, en el cual todos sus componentes se interrelacionan e influyen mutuamente.

- Reciclaje de desechos tóxicos: analizar información arrojada en el instrumento aplicado en la localidad.

- Calentamiento global (penetración del mar): Es un aspecto de vital importancia en la zona objeto de estudio dado la cercanía a la línea costera.

- Legales:

- Leyes sobre empleo: la ley 116 del Código del Trabajo emitida en 2014 por la Gaceta Oficial de la República de Cuba en su Capítulo 1 deja por sentado que el derecho de trabajo en Cuba, se sustenta en las relaciones de producción propias de un Estado socialista de trabajadores, que tiene como elemento esencial el trabajo y se aplica de conformidad con los fundamentos políticos, sociales y económicos dispuestos en la Constitución.

- Leyes sobre salud y seguridad laboral: En el Capítulo 2 de la misma ley anteriormente mencionada en su índice g), plantea y cito ...el derecho de los trabajadores a la seguridad y salud en el trabajo, mediante la adopción de medidas para la prevención de accidentes de trabajo y enfermedades profesionales.

\section{Fase 2: Diseño de configuración/ Planificación}

1. Descripción detallada del proyecto:

Producto: Boulevard Maroya 
Concepto: cultura, entretenimiento y religión.

El proyecto comunitario lleva el nombre de Boulevard Maroya, dado a la historia más precolombina de la ciudad. Este era el nombre de la india que bajaba al monte todas las noches desde la luna para bañarse en las aguas del río Hanabanilla, que corre entre las lomas del Guamuhaya (verdadero nombre geográfico del llamado Escambray).

Este proyecto tiene como misión unir la zona objeto de estudio con el centro turístico de la ciudad y de esta forma insertarla al desarrollo económico de la zona.

Para lograr esto se propone construir un boulevard que tomará dos cuadras, en donde se podrá transitar libremente por la calle, y teniendo en cuenta que es necesario alterar aspectos físicos en la zona para crear y mejorar el equipamiento para aumentar el atractivo del lugar se:

- Se pondrán bancos a ambos lados del boulevard.

- Se restaurarán y se pintarán las fachadas de las viviendas enclavadas en la zona permitiendo así el disfrute de los valores patrimoniales de estas edificaciones.

- Se construirán esculturas alegóricas a la cultura cienfueguera.

- Se construirán de 3 stands para ventas de bebidas y coctelería, souvenirs y de artículos operados por Palmares, Artex y asociados de la Asociación Cubana de Artistas y Artesanos.

- Se incorporarán nuevas luminarias para mejorar el servicio de alumbrado público.

- Se realizarán ventas de tarjetas para facilitar la conexión a internet de los visitantes haciendo uso de las redes wifi encontradas en la zona.

- En la entrada del boulevard desde el muelle se construirá una réplica de las puertas de la ciudad encontrada en el Parque Martí del centro histórico para dar la bienvenida formal a la ciudad a los crucerista.

- Vinculando a los moradores de la localidad, el proyecto generará empleos permitiendo la proliferación de la actividad por cuenta propia en función con la venta de souvernirs, artesanías, tallas de madera, pequeños espacios para la venta de café, jugos, refrescos y frutas.

- Existirá un Buró de Información al visitante, así como un Buro de Reservaciones operado por la Agencia Cubatur para excursiones etc.

- Existirán actividades en formato de talleres de creación con artistas de localidad y los pioneros de las escuelas primarias enclavadas en las cercanías al proyecto. (pintura, danza, escultura)

- Propiciará la interrelación directa entre moradores y visitantes. 
El espacio estará abierto a todo tipo de visitantes, los cuales podrán transitar por el boulevard y llegar hasta el muelle que recibe a los cruceristas, aunque existirán actividades en los horarios picos de arribo de cruceros a la bahía, así como en las despedidas de los mismos.

Estas actividades serán realizadas por un equipo del Consejo de Artes Escénicas de la Dirección Provincial de Cultura en conjunto con la Delegación Provincial del MINTUR y la Oficina de Patrimonio.

El recibimiento será dado con la emblemática canción: Cienfuegos en la ciudad que más me gusta a mí, de Benny Moré por ser un símbolo autóctono de la cultura cienfueguera.

La actividad que tendrá no más de 10 minutos estará acompañada de una representación por parte del mismo equipo del Consejo de Artes Escénicas basada en disfraces, estatuas vivientes y bailes de revivir personalidades, mitos, leyendas y momentos representativos de la cultura local. Como por ejemplos:

- El Benny Moré.

- India Guanaroca.

- India Maroya.

- La cueva Martin Infierno.

- Leyenda de Caonao y Jagua.

- Leyenda de Maroya.

- Leyenda la Dama de Azul.

- Leyenda El Japonés y Pasacaballo.

- La influencia francesa en la ciudad.

- Y otros.

En la Tabla No. 1 que se muestra a continuación, se exponen los aspectos esenciales relacionados con la conceptualización y el paquete de servicio. 
Tabla No. 1: Proceso de conceptualización y paquete de servicio.

\begin{tabular}{|l|l|l|l|}
\hline Entorno & Idea- Concepto & Paquete de servicio & Implementación \\
\hline Análisis PESTAL & $\begin{array}{l}\text { Cultura } \\
\text { Entretenimiento } \\
\text { Religión }\end{array}$ & $\begin{array}{l}\text { Beneficios Tangibles } \\
\text { e intangibles }\end{array}$ & \\
\hline
\end{tabular}

Fuente: Elaboración propia.

Tabla No. 2: Proceso de conceptualización y paquete de servicio.

\begin{tabular}{|c|c|c|}
\hline Paquete de servicio & beneficios & \\
\hline Tangibles & materiales & $\begin{array}{l}\text { - el boulevard } \\
\text { - personas } \\
\text { - representaciones artísticas. } \\
\text { - ventas de comidas, souvenirs y } \\
\text { artesanías. } \\
\text { - simulación de personajes } \\
\text { emblemáticos de la ciudad. } \\
\text {-embellecimiento de la zona. } \\
\text { - intercambio comunicativo entre } \\
\text { los moradores y trabajadores con } \\
\text { los visitantes. }\end{array}$ \\
\hline \multirow[t]{4}{*}{ Intangibles } & \multirow[t]{2}{*}{ sensoriales } & Emociones 5 sentidos \\
\hline & & $\begin{array}{l}\text { - sentido de la vista. (visión) } \\
\text {-sentido del olfato. (olor) } \\
\text {-sentido del gusto. (sabor) } \\
\text { - sentido del oído. (audición) } \\
\text {-sentido del tacto. }\end{array}$ \\
\hline & \multirow[t]{2}{*}{ psicológicos } & Emociones. \\
\hline & & $\begin{array}{l}\text {-alegría. } \\
\text {-reconocimiento. } \\
\text {-gratitud. } \\
\text {-afectividad. }\end{array}$ \\
\hline
\end{tabular}

Fuente: Elaboración propia. 
2- Diseño operativo: (componentes y sus actividades) Se incluye todo lo que hay que garantizar previamente para que el cliente pueda disfrutar del producto servicio que se describió. Una vez terminado se debe comprobar si ejecutando los Componentes y Actividades propuestos se alcanza el OG.

\section{Componentes y actividades:}

\section{1- Cambios estructurales en la zona.}

\section{Actividades:}

- Construcción mediante contrato con la Empresa Constructora de Obras de Ingeniería ECOING \# 12 de:

- Una réplica de la puerta de la ciudad en la entrada al Boulevard desde el muelle.

- Tres stands para ventas de bebidas y coctelería operado por Palmares, así como otro para souvenirs operado por Artex y de artículos operado por asociados de la Asociación Cubana de Artistas y Artesanos.

- Tres pequeños locales para asistir al visitante. Buro de información, reservación de excursiones y ventas de tarjetas de internet y para realizar llamadas operados por Infotour, Cubatur y Cubacel respectivamente.

- Gestionar con el artista Juan García la conformación de un equipo de escultores locales para la construcción de 4 esculturas simbólicas: la India Maroya, el camarón como símbolo identitario de la ciudad, el escudo de la ciudad y una estatua que refleje la leyenda de Caonao y Jagua.

\section{2- Decoración del área.}

\section{Actividades:}

- Pavimentación de las calles mediante contrato con la Empresa Constructora de Obras de Ingeniería ECOING \# 12.

- Construcción y colocación de bancos a ambos lados del Boulevard a través de un convenio con la Oficina de Patrimonio.

- Pintar las fachadas de las viviendas mediante gestión con el Consejo de la Administración Municipal.

- Mejorar el alumbrado público mediante contrato con la Empresa Eléctrica Provincial.

\section{3- Articulación con los grupos de interés en la comunidad.}




\section{Actividades:}

- Realización de talleres de creación a través de la gestión con las escuelas primarias y con los artistas plásticos de la localidad.

- Coordinar con los trabajadores por cuenta propia del área para su inserción en el Boulevard.

- Diseño e impresión de pancartas con imágenes que fomenten la socialización de los moradores con los visitantes a través de contrato con Publicitur.

- Implementación de un programa básico de formación en función de las buenas prácticas de la gestión turística, coordinado e impartido por FORMATUR.

- Realización de círculos de interés en función del cuidado medioambiental mediante la coordinación con las escuelas primarias de la localidad y con la Dirección Provincial del CITMA.

- Realización de charlas en la comunidad para promover la historia y la cultura cienfueguera y así su inserción dentro del producto turístico cubano a través de la gestión con la Oficina del Historiador de la Ciudad.

\section{4- Espectáculo de bienvenida.}

\section{Actividades:}

- Gestionar con el equipo acreditado por el Consejo de las Artes Escénicas en conjunto con la Dirección Provincial de Cultura para la realización de la actividad de bienvenida.

- Firmar un convenio con el Consejo de las Artes Escénicas para que el desarrollo del espectáculo sea en función de los mitos, leyendas y personalidades antes mencionados, bajo la modalidad de performance, disfraces, actuación de títeres y estatuas vivientes, brindándose una amplia panorámica de la cultura cienfueguera,

Se hace necesario esclarecer que en esta investigación el procedimiento se realiza hasta la segunda actividad de la fase diseño de configuración, o sea hasta el diseño operativo del proyecto, pues debido al tiempo que lleva su ejecución, y los términos de tiempo para efectuar la investigación se hace imposible la continuidad de las siguientes etapas.

\section{Conclusiones}

- Los resultados alcanzados, las bases diseñadas y la integración de los diferentes componentes, para el proyecto comunitario, constituyen una herramienta de vital 
importancia para insertar la zona objeto de estudio al desarrollo turístico del Centro Histórico de la ciudad.

\section{Referencias bibliográficas.}

Ley No. 81, Protección Medioambiental aprobada en el 1997 por el Parlamento Cubano

Ley 116 del Código del Trabajo emitida en 2014 por la Gaceta Oficial de la República de Cuba

Ley de Inversión Extranjera emitida por la Gaceta Oficial de la República de Cuba)

Partido Comunista de Cuba (PCC). (2011). Lineamientos de la política económica y social del Partido y la Revolución [Internet]. La Habana, Cuba.CitedJanuary20,2013.Availablefromhttp://www.cubadebate.cu/noticias/20I(VII/()9/d escargue-en-cubadebate-elproyeclc[-de-lineamienlos-de-la-polilica-economica-y-socialdel-pcc/.

PMBOK (2013). Project Management Book of Nnowledge (PMBOK) Fifth Edition Cited: 2 de enero de 2016. Available from:https://www.pmi.org/pmbok-guidestandards/foundational/pmbok

Rodriguez, José Luis. Una primera mirada a la economía cubana: Resultados de 2015 y perspectivas de 2016.

Zamora, T., Gestión y Evaluación de Proyectos Turísticos. Libro de texto docente. Universidad de La Habana, Manuscrito presentado para publicación. 2009

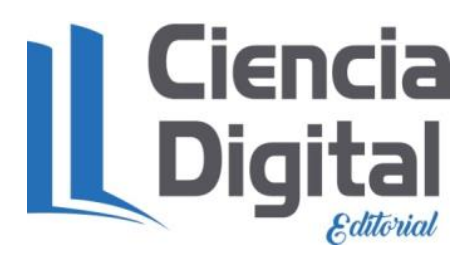




\section{Para citar el artículo indexado.}

Sarduy M. . (2018). Proyecto comunitario (Turístico-Cultural): Boulevard Maroya. (Validación). Revista electrónica Ciencia Digital 2(3), 173-186. Recuperado desde: http://cienciadigital.org/revistacienciadigital2/index.php/CienciaDigital/article/view/145/13 $\underline{0}$

El artículo que se publica es de exclusiva responsabilidad de los

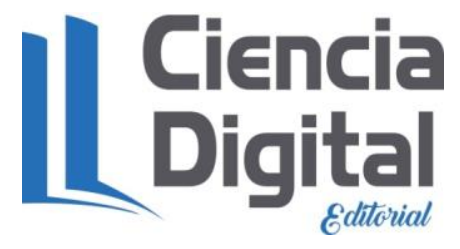
autores y no necesariamente reflejan el pensamiento de la Revista Ciencia Digital.

El articulo queda en propiedad de la revista y, por tanto, su publicación parcial y/o total en otro medio tiene que ser autorizado por el director de la Revista Ciencia Digital.
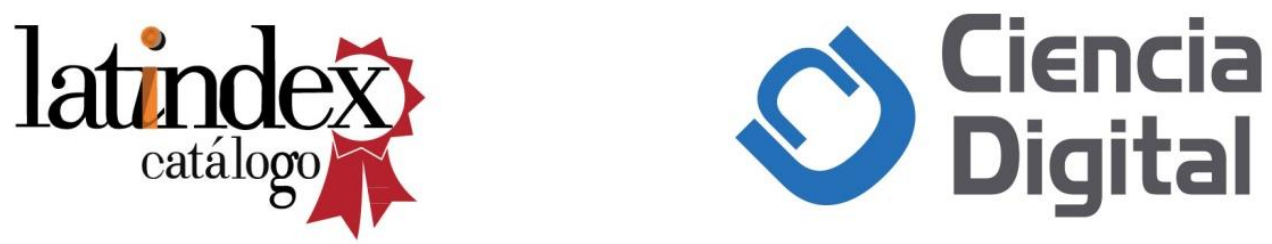